\title{
Functional Analysis of Pathogenicity Proteins of the Potato Cyst Nematode Globodera rostochiensis Using RNAi
}

\author{
Qing Chen, ${ }^{1}$ S. Rehman, ${ }^{2}$ G. Smant, ${ }^{2}$ and John T. Jones ${ }^{1}$ \\ ${ }^{1}$ Plant-Pathogen Interactions Programme, Scottish Crop Research Institute, Invergowrie, Dundee, DD2 5DA, U.K.; \\ ${ }^{2}$ Laboratory of Nematology, Department of Plant Sciences, Wageningen University, Binnenhaven 5, 6709PD Wageningen, \\ The Netherlands
}

Submitted 29 November 2004. Accepted 15 February 2005.

\begin{abstract}
RNA interference (RNAi) has been used widely as a tool for examining gene function and a method that allows its use with plant-parasitic nematodes recently has been described. Here, we use a modified method to analyze the function of secreted $\beta-1,4$, endoglucanases of the potato cyst nematode Globodera rostochiensis, the first in vivo functional analysis of a pathogenicity protein of a plantparasitic nematode. Knockout of the $\beta-1,4$, endoglucanases reduced the ability of the nematodes to invade roots. We also use RNAi to show that $g r$-ams-1, a secreted protein of the main sense organs (the amphids), is essential for host location.
\end{abstract}

Additional keywords: amphid-secreted protein, cellulase, gene silencing, invasion.

Plant-parasitic nematodes are pathogens of almost all crops grown worldwide, causing damage valued at over $\$ 75$ billion per annum (Sasser and Freckmann 1987). The most economically important species are the biotrophic root-knot (Meloidogyne spp.) and cyst-forming (Heterodera and Globodera spp.) nematodes. Feeding by these nematodes is not a passive process. Invasive-stage juveniles invade roots of potential host plants and migrate to a cell suitable for feeding site induction. In a susceptible interaction, the nematode induces the formation of a feeding site, a highly metabolically active multinucleate structure on which the nematode feeds for the next 3 to 4 weeks. Expression patterns of many plant genes, including those controlling fundamentally important developmental processes such as the cell cycle, are adjusted in the feeding site. The molecular processes underlying feeding site development have been reviewed recently (Gheysen and Fenoll 2002). Secretions of the subventral and dorsal esophageal gland cells have been the subject of intense study because it is thought that they play important roles in many aspects of the hostparasite interaction, including host invasion and induction and maintenance of the feeding site (Davis et al. 2000). As a result of these studies, most notably the use of expressed sequence tags (Popeijus et al. 2000a), genes encoding many secreted proteins have been identified in potato cyst nematodes $(\mathrm{PCN})$

Corresponding author: John Jones; Telephone: +44 1382 562731; Fax: +44 1382 562426; E-mail: jjones@scri.sari.ac.uk

Current address of Q. Chen: H. Lee Moffitt Cancer Center \& Research Institute, 12902 Magnolia Drive, Tampa, FL 33612, USA. and other plant-parasitic nematodes. Some secreted proteins have functional roles in the host-parasite interaction that can be readily tested. Genes that encode secreted plant cell-walldegrading enzymes (Popeijus et al. 2000b; Smant et al. 1998), antioxidant proteins (Robertson et al. 2000), and chorismate mutase (Jones et al. 2003) have a predicted biochemical function that can be verified in vitro. However, the roles of these proteins in vivo remain to be tested. Many other genes have been identified that encode secreted proteins and are expressed solely in the esophageal gland cells and, therefore, are candidates for proteins that are important in host-parasite interactions, but that have no easily predictable function on the basis of sequence similarity. Therefore, systems that allow gene function to be tested in vivo need to be developed and tested.

In Caenorhabditis elegans and many other organisms, RNA interference (RNAi) has been used to investigate gene function in detail. This technique uses the fact that exposure of an organism to double-stranded (ds)RNA from a gene of interest causes post-transcriptional silencing of the endogenous gene and allows a null phenotype to be mimicked (Fire et al. 1998). RNAi has been used for genomics scale studies in C. elegans (Maeda et al. 2001); however, until recently, it could not be used with plant-parasitic nematodes, because the invasivestage juveniles did not to take up dsRNA from solution. Recently, Urwin and associates (2002) described a method that uses a neurotransmitter, octopamine, to induce feeding in invasive second-stage juveniles (J2) of PCN, allowing uptake of dsRNA from solution, and used this method to knock out several genes, including one encoding a digestive protease.

Here, we describe some modifications to this technique that allow it to be used to perform functional analysis of a variety of PCN proteins, including potential pathogenicity proteinssecreted endoglucanases. A family of genes encoding secreted $\beta-1-4$ endoglucanases has been identified in PCN (Smant et al. 1998) and other plant-parasitic nematodes (Rosso et al. 1999). These genes are expressed in the subventral gland cells and are secreted from the nematode during migration through the host root (De Boer et al. 1999; Wang et al. 1999). This, coupled with the observation that the plants own cell-wall-degrading enzymes are responsible for the degradation of the cell walls within the syncytium (Goellner et al. 2001), suggests that the functional role of the nematode $\beta-1-4$ endoglucanases is degradation of plant tissues in order to facilitate invasion and migration. We show that the secreted cellulases of PCN are essential for successful invasion of host tissues. In addition, we demonstrate that a secreted protein of the amphids, the main sense organs of nematodes, is critical for host location. 


\section{RESULTS}

A modified protocol combining features described by Urwin and associates (2002), most notably the use of octopamine to induce feeding, and features of the method used for highthroughput screening in C. elegans (Maeda et al. 2001) (discussed below), allowed reproducible silencing of the genes being tested. The addition of spermidine to the soaking mix and incubation of the nematodes for $24 \mathrm{~h}$ (compared with the $4 \mathrm{~h}$ described by Urwin and associates [2002]) seemed to be important factors. For example, when reverse-transcription polymerase chain reaction (RT-PCR) was used to compare levels of gene expression in nematodes after $4 \mathrm{~h}$ of exposure to dsRNA, no reproducible drop in levels of the endogenous mRNA was observed with either the ams- 1 or eng genes (not shown).

\section{An amphid-secreted protein is essential for sense organ function.}

The amphids of PCN contain seven nerve processes exposed to the external environment that are bathed in secretions produced by a sheath cell that forms the cavity of the amphid (Jones et al. 1994). Although little is known about the role of the secretions produced by the sheath cell, secretions of insect sense organs are important for their function (Vogt et al. 1990), and nematicides that target sensory perception in nematodes cause changes in the appearance of these secretions (Trett and Perry 1985). Therefore, it is likely that the amphid secretions are important for the function of these sense organs. We attempted to silence a gene $(G r$-ams- 1$)$ that encodes a secreted protein and is expressed solely in the sheath cells of the amphids of PCN (Jones et al. 2000) and that, therefore, is likely to encode a protein forming part of the amphid secretions.

RT-PCR experiments comparing expression of the Gr-ams-1 gene in dsRNA treated and control nematodes showed that the RNAi procedure resulted in a downregulation of the Gr-ams-1 mRNA (Fig. 1). Expression of a control gene (actin) was, by contrast, similar in both treated and untreated samples (Fig. 1). Infection studies showed that the treated nematodes were almost completely unable to locate and invade host plants compared with the controls (Fig. 2). All nematodes (control and dsRNAtreated) were examined under a microscope after treatment and sterilization. In all cases, the nematodes were alive and moving normally before being used for experiments.

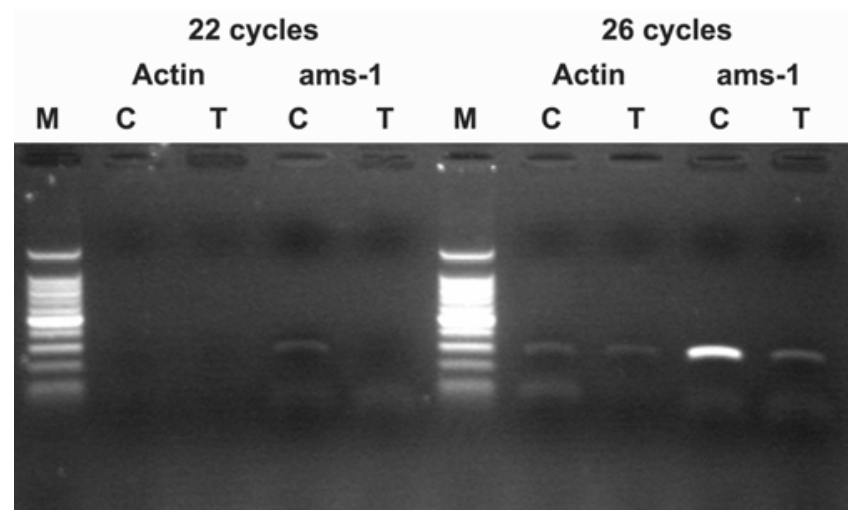

Fig. 1. Reverse-transcription polymerase chain reaction analysis of levels of ams-1 and actin mitochondrial RNA in control nematodes (C) and nematodes exposed to ams-1 double-stranded (ds)RNA. After 22 cycles, a band of the expected size is amplified using the ams-1 primers from control nematodes but no band is present in nematodes exposed to ams-1 dsRNA. After 26 cycles, the ams- 1 band is present in all samples but is present at far higher levels in control samples. Amplification of a band from actin is similar in control and ams- 1 samples. These data indicate a specific reduction in ams- 1 transcript in nematodes exposed to ams- 1 dsRNA. $M=100$ bp ladder.
RNAi of nematode cellulases leads to reduced infectivity.

A family of genes encoding secreted $\beta-1-4$ endoglucanases has been identified in PCN that have been suggested to degrade plant tissues in order to facilitate invasion and migration. Our RNAi experiments supported this. RT-PCR experiments showed a decrease in the levels of the mRNA of engl (Fig. 3) when compared with control genes. Some decrease in the levels of eng3/4 also was observed (Fig. 3). Invasion studies showed that treatment of $\mathrm{J} 2$ with cellulase dsRNA significantly reduced $(P \leq 0.002)$ the ability of the nematodes to infect plants. Although data was variable, on average, almost twice as many untreated nematodes were present in each plant compared with those treated with dsRNA (an average of 11.9 nematodes per plant compared with an average of 6 nematodes per plant). We compared the developmental fate of those nematodes that were able to infect plants. No differences were found in nematode development (male or female) that could be attributed to treatment with dsRNA. The proportion of feeding nematodes that had a greatly swollen appearance (suggesting development to females) was $44 \%$ in control samples compared with $60 \%$ in dsRNA-treated nematodes. Far fewer nematodes invaded each plant in dsRNA-treated nematodes, which may explain the apparent shift in sex ratio toward female development. Clearly, there was no evidence of a trend toward male development in dsRNA-treated nematodes. The location of nematodes (but not the feeding sites) within the plant root also was compared. In control samples, $40 \%$ of the nematodes were lying close to the vascular tissue of the plant roots while the remaining $60 \%$ had settled in more peripheral root tissues. In nematodes treated with dsRNA, these figures were 37.5 and $62.5 \%$,

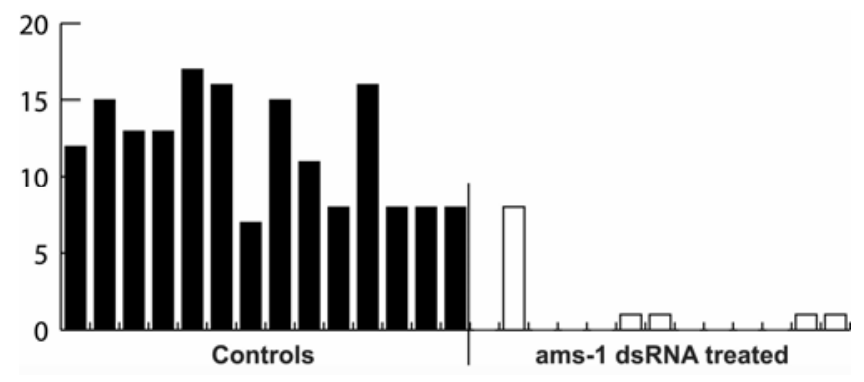

Fig. 2. Numbers of Globodera rostochiensis invading roots of potato after exposure to control treatment or ams-1 double-stranded (ds)RNA. Each column represents a single plant.

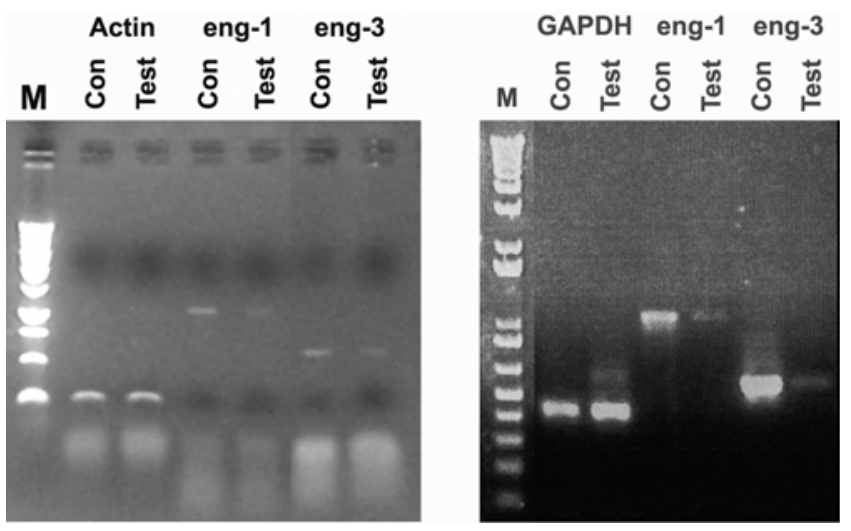

Fig. 3. Reverse-transcription polymerase chain reaction analysis of levels of endoglucanase gene expression compared with two control genes in control nematodes (Con) and nematodes exposed to eng-1/2 double-stranded (ds)RNA. Levels of eng-1 and eng-3 mRNA are reduced in samples exposed to eng-1/2 dsRNA. Levels of two control genes, actin (left panel) and $G A P D H$ (right panel), are similar in control and test samples. $\mathbf{M}=100$-bp DNA ladder. 
respectively. This suggests that, for the cellulase, a proportion of the nematodes were affected by the RNAi procedure with other nematodes unaffected.

\section{DISCUSSION}

The data presented here show, for the first time, that RNAi can be used to analyze the function of a pathogenicity factor of a plant-parasitic nematode. We found that the efficiency of the procedure could be enhanced by combining features of the method described by Urwin and associates (2002), with some of those used for high-throughput analysis of $C$. elegans genes. A 24-h incubation period, compared with the $4 \mathrm{~h}$ used by Urwin and associates (2002), seemed to be particularly important. A comparison of the data obtained from a gene expressed in sense organs with a gene expressed in the subventral gland cells showed that a certain amount of variability was present, with the $a m s-1$ gene seemingly far more susceptible to RNAi than the eng genes. This variation may be gene specific (possibly associated with levels of expression of the genes) or may relate to the tissues in which the genes are expressed. It also is possible that the fragment targeting ams- 1 contained more regions particularly suited for generation of silencing RNAs than the fragment targeting the endoglucanase genes, or that the different-sized fragments of dsRNA used to silence the two genes had an effect (although a larger fragment was used for the endoglucanases). Indeed, there are many possible reasons for the observed differences in silencing efficiency. Because the mechanisms underlying gene silencing are still in the process of being uncovered, it is not possible to state with any confidence the real reasons for the observed effects.

Functional experiments using pathogenicity genes may give phenotypes that require detailed analysis or that are difficult to score. In order to verify that the RNAi method was working and could be used for in vivo studies, we first sought to disrupt the function of a protein of the main sense organs (the amphids) of PCN. The rationale for this was that disruption of sense organ function should give rise to an easily scored phenotype, an inability to locate host roots. The function of the AMS-1 amphid-secreted protein is unknown; however, the data presented here suggest that it is essential for normal sense organ function. In $C$. elegans, at least eight genes encoding proteins similar to AMS-1 are present. The function of these genes has been examined as part of large-scale RNAi studies; however, these studies have not revealed a role for any of the $C$. elegans genes in sensory perception. However, the scale of these studies mean that few phenotypes are analyzed in detail and it is likely that a subtle effect, such as disruption of sensory perception, would be missed in such screens. We have demonstrated previously that at least one other similar protein is present in Globodera rostochiensis. However, the gene encoding this other protein is expressed in the hypodermis (Jones et al. 2000) and, therefore, it is possible that this group of proteins has a role in the secretion process in a variety of nematode tissues.

Plant-parasitic nematodes have been shown to produce a variety of endogenous plant cell-wall-degrading enzymes. These enzymes are secreted by preparasitic $\mathrm{J} 2$ and by parasitic $\mathrm{J} 2$ during migration of the nematodes within the root (De Boer et al. 1999). Expression of the plants own endogenous cellwall-degrading enzymes is induced in nematode feeding sites in order to achieve the breakdown of the plant cell walls that accompanies development of the syncytium (Goellner et al. 2001). Therefore, it is thought that the role of the nematode cellulases is to soften and break down plant cell walls in order to assist nematode migration through the root. Our data further support this and show that RNAi can be used as a tool for investigating the role of nematode-secreted proteins in the host- parasite interaction. However, experiments using the engtreated nematodes suggested that, in this case, a proportion of the nematodes were not affected by the dsRNA treatment. These nematodes infected plants and developed normally. Although enough nematodes were affected to allow the expected phenotype to be detected, analyzing a phenotype where the gene being silenced is of unknown function is likely to be challenging if only a proportion of the nematodes are affected.

\section{MATERIALS AND METHODS}

\section{Biological material.}

$G$. rostochiensis was maintained in a glasshouse on the susceptible potato (Solanum tuberosum) cv. Désirée using standard protocols (Jones et al. 1996). Invasive-stage juveniles were obtained by soaking dried cysts for 5 days in sterile distilled water (SDW) followed by incubation in tomato root diffusate prepared as described by Blair and associates (1999). Nematodes harvested for RNAi experiments were used within $24 \mathrm{~h}$ of hatching.

Potato plants (cv. Désirée) used for invasion studies were maintained in sterile tissue culture using standard protocols (Kumar 1995).

\section{Generation of dsRNA.}

Regions of cDNA were selected for silencing by RNAi and PCR primers were designed to amplify the selected fragment. Two PCR products were generated for each gene, with the T7 promoter sequence incorporated at the $5^{\prime}$ end of either the sense or the antisense strand. For the Gr-ams-1 gene, a region from nucleotides 171 to 415 of the cDNA sequence (accession number AJ270995) was used. Primers AMSF, AMST7F, AMSR, and AMST7R (discussed below) were used to generate this fragment. For the Gr-eng genes, a region from nucleotides 299 to 608 of the $G r$-eng-1 cDNA sequence (accession number AF004523) was used because this showed very high (over 98\%) similarity to the Gr-eng-2 (accession number AF004716) cDNA sequence and also had high similarity to the Gr-eng-3/4 sequences (accession numbers AF408155 and AF408156), including stretches of 20 nucleotides with over 95\% identity, suggesting that it should be possible to reduce expression of all characterized endoglucanase genes with the same dsRNA. Primers ENGF, ENGT7F, ENGR, and ENGT7R (discussed below) were used to generate this fragment. PCR products were purified using a PCR purification kit (Qiagen, Valencia, CA, U.S.A.), quantified by spectrophotometry, and used as the templates for in vitro transcription reactions using a Megascript RNAi kit (Ambion, Austin, TX, U.S.A.) following the manufacturer's instructions. The single-stranded RNAs generated from each of the two strands then were annealed by heating to $75^{\circ} \mathrm{C}$ for $5 \mathrm{~min}$ and were allowed to cool to room temperature. The dsRNA was treated with DNAse to remove template, purified using columns supplied in the Megascript kit, and precipitated under ethanol. The dsRNA was resuspended in diethylpyrocarbonate-treated water (Sambrook et al. 1989) and quantified by spectrophotometry.

\section{RNAi by soaking.}

A method was developed based on that described by Urwin and associates (2002) but incorporating features of the soaking method used for C. elegans studies (Maeda et al. 2001). Several thousand $\mathrm{J} 2$ were soaked in $0.25 \times \mathrm{M} 9(1 \times \mathrm{M} 9=43.6 \mathrm{mM}$

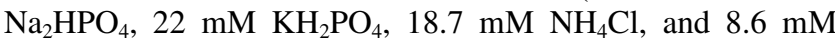
$\mathrm{NaCl}$ ) containing $50 \mathrm{mM}$ octopamine, $3 \mathrm{mM}$ spermidine, $0.05 \%$ gelatin, and dsRNA at between 2 and $5 \mathrm{mg} / \mathrm{ml}$ for $24 \mathrm{~h}$ in the dark at room temperature on a rotator. Control samples were incubated in the same solution but without dsRNA. After 
soaking, the nematodes were washed three times in $0.25 \times \mathrm{M} 9$ to remove dsRNA. An aliquot of the dsRNA was checked on an agarose gel stained in ethidium bromide to verify that degradation had not occurred during the soaking process. An aliquot of the nematodes was removed for invasion studies and the remaining nematodes were frozen in liquid nitrogen and stored at $-80^{\circ} \mathrm{C}$ before being used for RNA extractions. The fluorescein isothiocyanate (FITC) in the soaking solution and hand sorting of nematodes showing FITC uptake described by Urwin and associates (2002) was found to be unnecessary and, therefore, was omitted from the protocol. RNAi experiments were repeated on at least three separate occasions and, where possible, in both laboratories participating in this study.

\section{Invasion studies.}

Internodal cuttings were taken from $S$. tuberosum (cv. Désirée) grown in sterile culture and grown in 12-well plates containing MS20 medium. Preliminary studies showed that invasion rates of such cuttings were similar to those in pot experiments (L. Castelli, unpublished data). Nematodes treated with dsRNA and control nematodes were sterilized by soaking for $30 \mathrm{~min}$ in $0.1 \%$ chlorohexidine digluconate and cetyltrimethylammonium bromide at $0.5 \mu \mathrm{g} / \mu \mathrm{l}$ followed by two 5 -min washes in $0.01 \%$ Tween 20 with a final rinse in SDW. The nematodes were checked under a light microscope after sterilization to ensure that they were still alive. A total of 100 nematodes were used to infect each plant. Plants were stained in acid fuchsin (Bridge et al. 1982) 2 weeks later in order to determine the numbers of nematodes that had invaded and set up feeding sites. Replicate experiments were performed and the entire experiment was repeated. Plant root systems were of approximately equal size and mass (not shown).

\section{RT-PCR.}

RNA was extracted using a Micro Fast Track kit (Invitrogen, Carlsbad, CA, U.S.A.) following the manufacturer's instructions. Each batch of mRNA was checked for contamination with gDNA by performing a PCR reaction with actin primers (below) before use. The entire mRNA extraction for each sample was converted to first-strand cDNA using a SMART cDNA synthesis kit (Clontech, Palo Alto, CA, U.S.A.) following the manufacturer's instructions. Aliquots of the resulting cDNA then were used in PCR reactions containing $1 \times$ Taq buffer (Promega Corp., Madison, WI, U.S.A.), $1.5 \mathrm{mM} \mathrm{MgCl}_{2}, 200$ $\mu \mathrm{M}$ dNTPs, $1 \mu \mathrm{M}$ each primer (below), and 2.5 units of Taq DNA polymerase (Promega Corp.). Cycling conditions consisted of one cycle of denaturing at $94^{\circ} \mathrm{C}$ for $2 \mathrm{~min}$ followed by 35 cycles of $30 \mathrm{~s}$ of denaturing at $94^{\circ} \mathrm{C}, 30 \mathrm{~s}$ of annealing at 50 to $55^{\circ} \mathrm{C}$ (depending on the primer combination), and $30 \mathrm{~s}$ of extension at $72^{\circ} \mathrm{C}$. Aliquots of the reaction were removed after 22, 26, 30, and 35 cycles. For each experiment, four PCR reactions were set up: two reactions using control primers (ACTF and ACTR) designed to amplify a fragment of the actin cDNA from the control and dsRNA-treated cDNA samples, and two reactions using primers (XXTESTF and XXTESTR) designed to amplify a fragment of the gene being silenced. In all cases, the latter primer set was designed to amplify a different region of the gene than that targeted by the dsRNA fragment. PCR products were visualized on $1.5 \%$ agarose gels stained with ethidium bromide using standard protocols (Sambrook et al. 1989).

\section{Primers.}

The sequences of the primers used in this study were: AMSF: 5'CAGGGCCAATGCCGGAATAT3', AMST7F: 5'GT AATACGACTCACTATAGGGCAGGGCCAATGCCGGAATA T3', AMSR: 5'GGAGACTCTCAGTGCTTCAC3', AMST7R:
5'GTAATACGACTCACTATAGGGGGAGACTCTCAGTGCT TCAC3', ENGF: 5'GTTGCCGTGATTGAGGC3', ENGT7F: 5'GTAATACGACTCACTATAGGGGTTGCCGTGATTGAGG C3', ENGR: 5'TCTTTGATCGGATTCTGCGA3', ENGT7R: 5'GTAATACGACTCACTATAGGGTCTTTGATCGGATTCT GCGA3', ACTF: 5'ATGTGYGAYGARGARGTNGC3', ACTR: 5'ATYTTYTCCATRTCRTCCCA3', AMSTESTF: 5'CCGCCT CAATGAACTGCATT3', AMSTESTR: 5'TACTTACTCTCTT TCTCAGAGTATTA3', ENG1/2TESTF: 5'CACATTGTGTTC TGTAACGC3', ENG1TESTR: 5'GTTGAGACAACAGTGAC GCT3', ENG2TESTR: 5'CAGCGGCAGGTTTGGCCGGAG GCG3', ENG3TESTF: 5'GGCAACCGCTTTTGGGTG3', and ENG3TESTR: 5'CCAAAGTGCCAACTCTTTGAGA3'.

\section{ACKNOWLEDGMENTS}

This work was funded by Scottish Executive Environment and Rural Affairs Department project SCR/561/01 and by European Union grant number QLK5-1999-1501. The technical support of A, Holt and A, Paterson is gratefully acknowledged.

\section{LITERATURE CITED}

Blair, L., Perry, R. N., Oparka, K., and Jones, J. T. 1999. Activation of transcription during the hatching process of the potato cyst nematode Globodera rostochiensis. Nematology 1:103-111.

Bridge, J., Page, S. L. J., and Jordan, S. M. 1982. An improved method for staining nematodes in roots. Page 171 in: Rothamsted Experimental Station Annual Report 1981. Hertfordshire, England.

Davis, E. L., Hussey, R. S., Baum, T. J., Bakker, J., Schots, A., Rosso, M. N., and Abad, P. 2000. Nematode parasitism genes. Annu. Rev. Phytopathol. 38:365-396.

De Boer, J., Yan, Y., Wang, X., Smant, G., Hussey, R. S., Davis, E. L., and Baum, T. J. 1999. Developmental expression of secretory beta-1,4endoglucanases in the subventral esophageal glands of Heterodera glycines. Mol. Plant-Microbe Interact. 12:663-669.

Fire, A., Xu, S., Montgomery, M. K., Kostsas, S. A., Driver, S. E., and Mello, C, C. 1998. Potent and specific genetic interference by doublestranded RNA in Caenorhabditis elegans. Nature 391:806-811.

Gheysen, G., and Fenoll, C. 2002. Gene expression in nematode feeding sites. Annu. Rev. Phytopathol. 40:191-219.

Goellner, M., Wang, X., and Davis, E. L. 2001. Endo B1-4 glucanase expression in compatible plant-nematode interactions. Plant Cell 13:2241-2255.

Jones, J. T., Curtis, R. H., Wightman, P. J., and Burrows, P. R. 1996. Isolation and characterization of a putative collagen gene from the potato cyst nematode Globodera pallida. Parasitology 113:581-588.

Jones, J. T., Furlanetto, C., Bakker, E., Banks, D. A., Blok, V. C., Chen, Q., Phillips, M. S., and Prior, A. 2003. Characterisation of a chorismate mutase from the potato cyst nematode Globodera pallida. Mol. Plant. Pathol. 4:43-50.

Jones, J. T., Perry, R. N., and Johnston, M. R. L. 1994. Changes in the ultrastructure of the amphids of the potato cyst nematode during development and infection. Fundam. Appl. Nematol. 17:369-382.

Jones, J. T., Smant, G., and Blok, V. C. 2000. SXP/RAL2 proteins of the potato cyst nematode Globodera rostochiensis: Secreted proteins of the hypodermis and amphids. Nematology 2:887-893.

Kumar, A. 1995. Agrobacterium-mediated transformation of potato genotypes. Pages 121-128 in: Agrobacterium Protocols. Methods In Molecular Biology. K. V. Gratland and M. R. Davey, eds. The Humana Press, Totowa, NJ, U.S.A.

Maeda, I., Kohara, Y., Yamamoto, M., and Sugimoto, A. 2001. Large scale analysis of gene function in Caenorhabditis elegans by high-throughput RNAi. Curr. Biol. 11:171-176.

Popeijus, H., Blok, V. C., Cardle, L., Bakker, E., Phillips, M. S., Helder, J., Smant, G., and Jones, J. T. 2000a. Analysis of genes expressed in second stage juveniles of the potato cyst nematodes Globodera rostochiensis and $G$. pallida using the expressed sequence tag approach. Nematology 2:567-574.

Popeijus, H., Overmars, H., Jones, J. T., Blok, V. C., Goverse, A., Helder, J., Schots, A., Bakker, J., and Smant, G. 2000b. Degradation of plant cell walls by a nematode. Nature 406:36-37.

Robertson, L., Robertson, W. M., Sobczak, M., Bakker, J., Tetaud, E., Ariyanayagam, M. R., Ferguson, M. A. J., Fairlamb, A. H., and Jones, J. T. 2000. Cloning, expression and functional characterisation of a thioredoxin peroxidase from the potato cyst nematode Globodera rostochiensis. Mol. Biochem. Parasitol. 111:41-49. 
Rosso, M. N., Favery, B., Piotte, C., Arthaud, L., D Boer, J. M., Hussey, R. S., Bakker, J., Baum, T. J., and Abad, P. 1999. Isolation of cDNA encoding a beta 1-4 endoglucanase in the root knot nematode Meloidogyne incognita and expression analysis during plant parasitism. Mol. Plant-Microbe Interact. 12:585-591.

Sambrook, J., Fritsch, E. F., and Maniatis, T., 1989. Molecular Cloning: A Laboratory Manual, 2nd ed. Cold Spring Harbor Laboratory Press, Cold Spring Harbor, NY, U.S.A.

Sasser, J. N., and Freckman, D. W. 1987. A world perspective on nematology: The role of the society. Pages 7-14 in: Vistas on Nematology. J. A. Veech and D. W. Dickerson, eds. Society of Nematologists, Marceline, MO, U.S.A.

Smant, G., Stokkermans, J. P. W. G., Yan, Y., De Boer, J. M., Baum, T., Wang, X., Hussey, R. S., Gommers, F. J., Henrissat, B., Davis, E. L., Helder, J., Schots, A., and Bakker, J. 1998. Endogenous cellulases in animals: Isolation of $\beta$-1,4-endoglucanase genes from two species of plant parasitic nematodes. Proc. Natl. Acad. Sci. U.S.A. 95:49064911.

Trett, M. W., and Perry, R. N. 1985. Effects of the carbamoyloxime, aldicarb, on the ultrastructure of the root lesion nematode, Pratylenchus penetrans (Nematoda: Pratylenchidae). Nematologica:321-334.

Urwin, P. E., Lilley, C. J., and Atkinson, H. J. 2002. Ingestion of doublestranded RNA by preparasitic juvenile cyst nematodes leads to RNA interference. Mol. Plant-Microbe Interact. 15:747-752.

Vogt, R. G., Rybczynski, R., and Lerner, M. R. 1990. The biochemistry of odorant reception and transduction. Pages 33-76 in: Chemosensory Information Processing. D. Schild, ed. Springer-Verlag, Berlin.

Wang, X., Meyers, D., Yan, Y., Baum, T. J., Smant, G., Hussey, R. S., and Davis, E. L. 1999. In planta localization of a beta 1-4 endoglucanase secreted by Heterodera glycines. Mol. Plant-Microbe Interact. 12:64-67. 